\title{
Über einige Textfehler in Kants Widerlegung des Idealismus.
}

\author{
Von Dr. Emil Wille.
}

Die Widerlegung des Idealismus (Kr. d. r. V. Aufl. 2. S. 274 ff.) enthält gewisse Rätsel, welche nicht durch Annahme von Textverderbnis gelöst werden können; indessen enthält sie auch einige Fehler des Abschreibers oder des Druckers, welche als solche zu erkennen und zu verbessern sind.

1. S. 276. Gegen Ende des „Beweises“ lesen wir: „Nun ist das Bewusstsein in der Zeit mit dem Bewusstsein der Möglichkeit dieser Zeitbestimmung notwendig verbunden." Aus dem Gedankenzusammenhange erhellt, dass das Bewusstsein der Bestimmung meines Daseins in der Zeit und das der Bedingung der Möglichkeit dieses Vorganges gemeint, und daher so zu lesen ist: „Nun ist das Bewusstsein dieser Bestimmung in der Zeit mit dem Bewusstsein der Bedingung der Möglichkeit dieser Zeitbestimmung notwendig verbunden." Jetzt erst verstehen wir den folgenden Schluss, in welchem übrigens gleichfalls etwas einzuschieben ist: „Also ist es auch mit der Existenz der Dinge ausser mir (muss lauten: mit dem der Existenz der Dinge ausser mir), als Bedingung der Zeitbestimmung, notwendig verbunden." Dass es so lauten muss, ist klar. Denn wenn das Bewusstsein dieser Zeitbestimmung mit dem Bew usstsein ihrer Bedingung verbunden ist, und selbige in der Existenz der Dinge ausser mir besteht, so muss es mit dem Bewusstsein dieser Existenz verbunden sein. Dazu kommt, dass nach dem erklärenden Zusatze, mit welchem der Beweis abschliesst, doch ein unmittelbares Bewusstsein des Daseins anderer Dinge ausser mir sich ergeben soll. Ich möchte noch hinzufügen, dass Bedingung der Möglichkeit eine unserem Philosophen sehr geläufige Verbindung ist.

2. Anmerkung 1. „Allein hier wird bewiesen, dass äussere Erfahrung eigentlich unmittelbar sei, dass nur vermittelst ihrer - " Wohl so: dass nur äussere Erfahrung eigentlich unmittelbar sei. Denn das Spiel, welches der Idealismus trieb, indem er nur innere als derartig zulassen wollte, wird ihm ja „umgekehrt vergolten“.

3. Am Ende der dazu gehörigen Note urter dem Texte: „Denn sich auch einen äusseren Sinn bloss einzubilden, würde das Anschauungsvermögen, welches durch die Einbildungskraft bestimmt werden soll, selbst vernichten." Ich bitte zu bedenken: Die Behauptung, dass man sich auch 
124 Dr. Emil Wille, Textfehler in Kants Widerlegung des Idealismus.

einen äusseren Sinn bloss einbilde, würde dasjenige Anschauungsvermögen, dessen Bestimmung durch die Einbildungskraft zu dieser Einbildung erforderlich wäre, doch nicht "vernichten“, sondern verneinen.

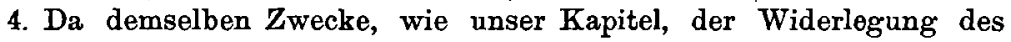
Idealismus, jene lange Anmerkung am Ausgange der Vorrede des Werkes gewidmet ist, wollen wir auch dort eine Stelle prüfen. „von etwas Beharrlichem, welches in mir nicht ist, folglich nur in etwas ausser mir Dieses Beharrliche ist nicht in etwas ausser mir, sondern etwas ausser mir. Am Besten ändern wir so: folglich nur von etwas ausser mir abhängt.

Dass weiter unten es nicht heissen darf: „denn diese kann sehr wandelbar und wechselnd sein", sondern: denn jene - darauf habe ich schon früher (in meinem Aufsatze: Verbesserung einiger Stellen in Kants Kr. d. r. V. Philosoph. Monatshefte 1890, XXVI, 399) hingewiesen. 